\title{
FECAL PELLETS OF AMERICAN PIKAS (OCHOTONA PRINCEPS) PROVIDE A CRUDE CHRONOMETER FOR DATING PATCH OCCUPANCY
}

\author{
Lyle B. Nichols ${ }^{1}$
}

\begin{abstract}
American pikas (Ochotona princeps) seem to be especially vulnerable to climate change, with recent extinctions of pika populations being attributed to global warming. Incomplete historical location records are currently used to examine changes in pika distributions. A method of determining recent pika distributions in the absence of historical records is needed. Here I report on changes over time of known-age pika fecal pellets up to 36 years old. Predictable changes in diameter, internal consistency, and color of pellets provide a method to approximate the dates of last occupation in patches where pikas have been extirpated.
\end{abstract}

Key words: Ochotona princeps, American pika, population decline, extinction, fecal pellets, decomposition, Bodie, California, distribution, global warming.

Resumen.-La pika Americana (Ochotona princeps) parece ser especialmente vulnerable al cambio climático, al que se atribuyen extinciones recientes de sus poblaciones. Actualmente, se están utilizando los registros históricos incompletos de ubicación para examinar cambios en las distribuciones de pikas. Es necesario un método para determinar distribuciones recientes de pikas a falta de registros históricos. Reporto aquí los cambios que se han observado con el transcurso del tiempo en bolitas fecales de hasta 36 años de antigüedad. Cambios predecibles en diámetro, consistencia interna y color de las bolitas proporcionan un método para datar aproximadamente cuánto hace que vivían pikas en sitios de los que han sido extirpadas.

American pikas (Ochotona princeps Richardson) are small (130-g), diurnal alpine lagomorphs that inhabit talus patches in the mountains of western North America (Smith and Weston 1990). Pikas are relatively easy to detect because they are diurnally active, highly vocal, and individually territorial, and because they leave behind obvious and distinctive sign, mainly hay piles and fecal pellets (Ray and Beever 2007, Beever et al. 2008, E.A. Beever personal communication). In addition, pikas have a combination of characteristics that may make them especially vulnerable to rapid climate change: intolerance to high ambient temperatures (MacArthur and Wang 1973, Smith 1974b), extreme specificity to talus, limited dispersal ability (Smith 1974a, Smith and Ivins 1983; but see Peacock 1997), and social intolerance (Smith and Ivins 1984). As such, pikas may be susceptible to local extirpation in the face of global warming (Beever 2002). Recent concern over pika adaptability to rapid climate change has led to research that examines ongoing changes in pika distribution in western North America (Beever 2002, Beever et al. 2003, Simpson 2009). Because of their sensitivity to climate change (Morrison and Hik 2008), pikas may be an ideal indicator species to monitor the effects of climate change.

Recently, a petition was filed to list pikas as threatened in the state of California, primarily because of deleterious impacts of global warming (Wolf et al. 2007). This petition was rejected, in part, for lack of evidence of range contractions in California (Carlson 2008). In fact, few published studies describe recent changes of pika distributions in California (see Beever 2002, Moritz et al. 2008). However, serious range contractions and local extirpations have been documented across Great Basin mountain ranges, immediately adjacent to the Sierra Nevada (Beever et al. 2003, Beever et al. 2008). Great Basin pika distributions are known for the entire Holocene Epoch because fossilized pika remains and pellets found in woodrat middens and other paleontological and archaeological sites extend back to the late Wisconsinan Glacial Episode (Grayson 2005). Even so, incomplete historical information regarding location of pika populations limits biologists' ability to accurately track distributional changes. Recent pika distributions can be inferred from 
standard sources (i.e., museum specimens, electronic databases such as MaNIS, Arctos, and the MVZ's online collections, as well as Grinnell 1918, Howell 1924, Bole 1938, Hall 1946, 1951, Durrant 1952, Hafner and Sullivan 1995, Verts and Carraway 1998, Beever et al. 2003). Yet, given the nonsystematic collecting methods employed in the late 19th and early 20th centuries, these sources also provide an incomplete picture of pika distribution. At locations with no prior records, a method is needed for assessment of recent pika distributions based on existing field evidence.

Pika populations in and adjacent to Bodie State Historic Park, California, were first reported by Severaid (1955) and have been extensively studied since that time (Smith 1974a, 1974b, 1980, Peacock and Smith 1997, Smith and Gilpin 1997, Moilanen et al. 1998, Clinchy, et al. 2002). A large subset of the Bodie metapopulation has been censused regularly from 1972 to the present. Census records of patch occupancy and extirpation allow an examination of known-age pika sign. Like other lagomorphs, pikas produce both hard and soft fecal pellets (Smith and Weston 1990). Pikas reingest their soft pellets, so these are rarely found in the field; however, hard pellets are produced in large quantities as the final waste product of digestion. Hard pellets are both durable and abundant in areas occupied by pikas. Cold, dry conditions probably slow both chemical weathering and biological activity that break down pellets. Smith and Gilpin (1997) noted that in dry alpine climates, old pika fecal pellets do not readily decompose and may persist for years. This durability allows identification of once-occupied talus patches, even though the populations have been extirpated.

Since the distribution of pikas is rapidly changing (Beever et al. 2003, 2008), a method is needed that allows researchers to document previous occupancy of now-vacant talus patches and to determine when populations on those patches likely died out. Here I use age-induced changes in known-age fecal pellet samples to develop a method of determining when a vacant talus patch was last occupied by pikas.

\section{StUdy AREA}

Bodie State Historic Park is located at $2500 \mathrm{~m}$ elevation in the Bodie Hills of Mono County, California. Bodie is separated from the Sierra
Nevada crest by approximately $35 \mathrm{~km}$ of Great Basin sage-scrub habitat with limited talus patches suitable for pika occupation. Hard-rock mining at Bodie in the late 19th and early 20th centuries left many ore dumps (often incorrectly referred to as "mine tailings") on the surface from Bodie Bluff south to Sugarloaf, a natural talus slope, in a swath approximately $4 \mathrm{~km}$ north to south and $1-1.5 \mathrm{~km}$ east to west. These ore dumps have been essentially unchanged since at least the 1940s and serve as artificial habitat islands for pikas (Smith 1974a, Smith and Gilpin 1997). Great Basin sage-scrub habitat separates islands of talus habitat. The Bodie flora is dominated by several species of sagebrush (Artemisia), currant (Ribes), and buckwheat (Eriogonum), as well as antelope bitterbrush (Purshia tridentata) and rubber rabbitbrush (Chrysothamnus nauseosus) (Severaid 1955). Pikas are known to have occupied Bodie ore dumps since at least 1900 and have occupied, at one time or another, nearly every favorable patch at Bodie (Severaid 1955, Smith 1974a). The pika population on a subset of Bodie ore-dump patches was censused in 1972 (Smith 1974a), 1977 (Smith 1980), 1989 (Smith and Gilpin 1997), 1991 (Smith and Gilpin 1997), 1992-2001 (unpublished data), 20032006 (unpublished data), and 2008 (unpublished data). No censuses were performed in 2002 or 2007. Census methods followed Smith (1974a, 1980). This long-term data set allowed accurate dating of patch occupation over the period covered by censuses.

\section{Methods}

\section{Short-term Pellet Aging}

On 27 June 2008, recently excreted pika pellets were collected from occupied territories and moved to two $15 \times 15$-cm baskets made of a double layer of galvanized mesh $(0.635-\mathrm{cm}$ mesh) on an unoccupied patch. Trays were surrounded by rocks on all sides and the top, but there was sufficient interstitial space to allow air circulation, as might be expected in an occupied pika latrine site at Bodie. Trays were examined about every week from 27 June through 15 August 2008 and once on 13 August 2009. Tray 1 initially contained 90 fresh pellets. All tray-1 pellets were measured across their widest point with calipers to the nearest $0.05 \mathrm{~mm}$. A few $(n$ $=10$ ) pellets were lost to wind on several occasions after 18 July. The final sample size for tray 1 was 80 pellets. Mean pellet diameters, 


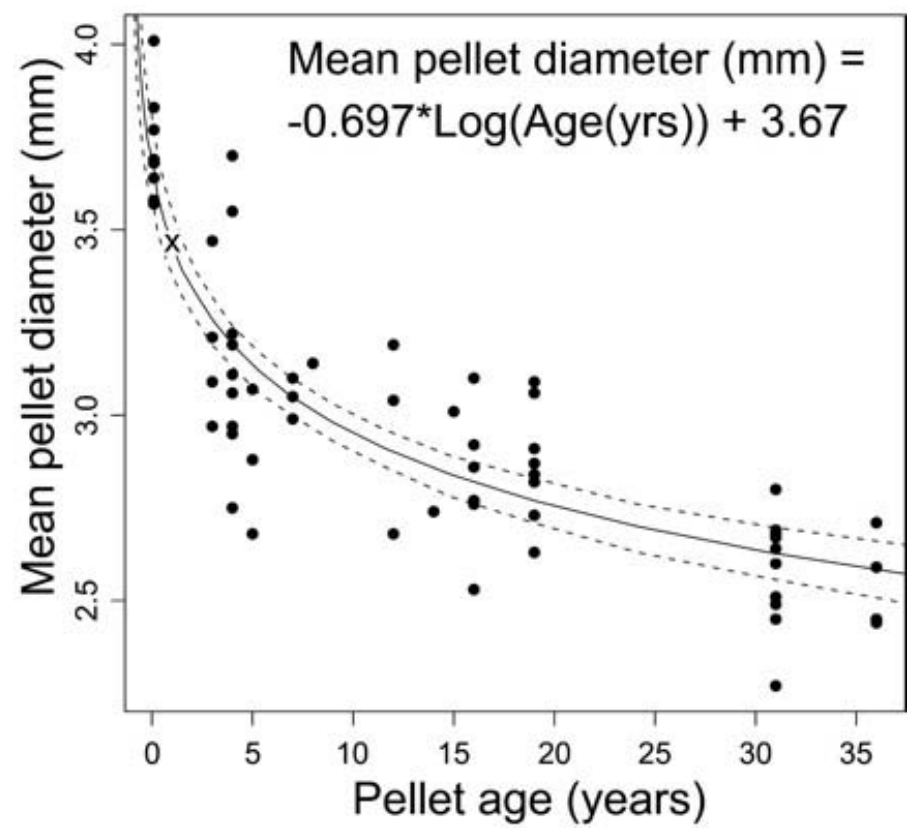

Fig. 1. Relationship between pellet age and mean pellet diameter (by latrine) for American pikas (Ochotona princeps) at Bodie State Historic Park, California. $\mathrm{R}^{2}=0.76, F_{1,60}=189.6, P<2.2 \times 10^{-16}$. Dotted lines represent the 95\% confidence interval. $\mathrm{X}$ indicates an independent sample from the short-term aging experiment.

measured each week from June through August 2009, were compared by ANOVA. Tray 2 contained approximately 200 fresh pellets that were examined weekly for qualitative changes in exterior and interior color and consistency. Two pellets from tray 2 were sampled destructively each week to examine their interior characteristics.

\section{Long-term Pellet Aging}

Pellets were collected between 15 June and 18 August 2008 from pika latrines $(n=62)$, for which ages were determined from long-term census data. For most latrines, a sample of pellets could be collected from between rocks by using a nickel spatula. On older ( $\geq 14$-year-old) latrines, pellets were sometimes located only after moving a few surface rocks. More than 40 pellets from each latrine were collected whenever possible. Samples were stored in individually labeled, sealed zipper-lock bags.

Forty randomly selected pellets were measured from each latrine. Pellets from a latrine were spread more or less evenly on a standard $21.59 \times 27.94 \mathrm{~cm}$ sheet of paper divided into 16 equally sized squares. Two coins were tossed to randomly choose a square, once to determine the square's row and once to determine its column. Pellets in the chosen square were measured starting in the upper left corner and continuing back and forth across and down that square until 40 pellets were measured. If fewer than 40 pellets were in the chosen square, another square was randomly selected using the same method. This process continued until 40 pellets were measured. For samples containing $\leq 40$ pellets, all pellets were measured. Each pellet was individually measured with calipers across its widest diameter to the nearest 0.05 $\mathrm{mm}$. All measurements of pellet diameter were made at the field site. To obtain dry weight, all pellets from a latrine that had diameter measurements were dried for 3 hours at $60{ }^{\circ} \mathrm{C}$, allowed to return to room temperature in a 47 $\times 25 \times 21-\mathrm{cm}$ desiccator lined with approximately $4 \mathrm{~cm}$ of soda lime, and weighed to the nearest $0.001 \mathrm{~g}$. Mean dry mass per pellet was calculated for each sample. The relationship between mean pellet diameter within latrines versus log age was analyzed by regression (Fig. 1). Log age was used because it seemed a priori that a logarithmic decay curve was appropriate for pellet decay and because this model represented the observed relationship better 


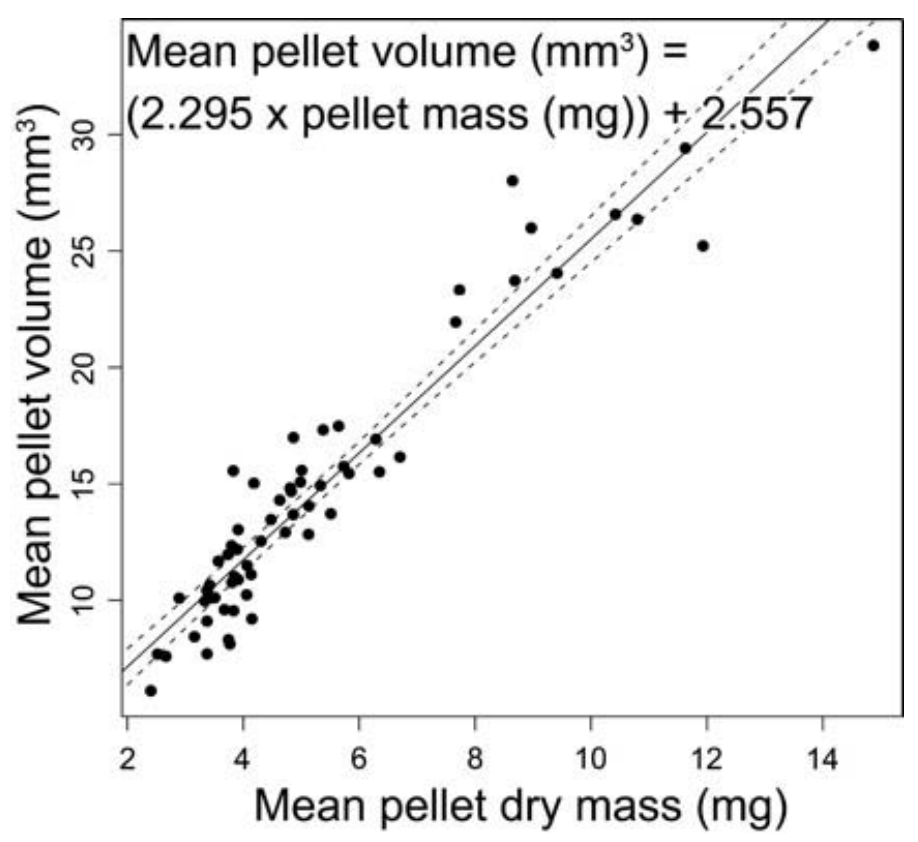

Fig. 2. Relationship between mean pellet mass by latrine and mean pellet volume (calculated as volume of a sphere with the measured mean pellet diameter) for American pikas (Ochotona princeps) at Bodie State Historic Park, California. $\mathrm{R}^{2}=0.91, F_{1,60}=608, P<2.2 \times 10^{-16}$. Dotted lines represent the $95 \%$ confidence interval.

than a linear model. The relationship between mean pellet volume per latrine and mean dry mass was analyzed with linear regression (Fig. 2). A qualitative examination was made for pellets aged $0,3,4,5,7,8,12,14,16,19,23$, 31 , and 36 years to determine differences in exterior and interior color and consistency. Two pellets from each age class were crushed to allow examination of interior color and consistency.

\section{Post hoc Test}

On 6 February 2010, 2 independent observers measured diameters of pellets from 24 of the known-age latrine samples in a blind test. The pellet samples had been stored in plastic zipper-lock bags at room temperature at Santa Monica College since August 2008. Pellets used were those not measured in the long-term pellet aging experiment but were from the same latrines. Each sample was labeled with only an identification number, so the observers did not know the age of the samples they measured. Observers randomly selected and measured 20 pellets using the same method described above. Paired $t$ tests were used to compare the 2 mean pellet diameters for each latrine (one from each observer) and to compare these latrine means with those used to construct Figure 1. The relationship between mean pellet diameter within latrines and log age was analyzed by regression as in the long-term aging experiment.

All statistical analyses were performed using $\mathrm{R}$, version 2.7.1 ( $\mathrm{R}$ Development Core Team 2008). Null hypotheses were rejected when $P$ $\leq 0.05$.

\section{RESUlTS}

\section{Short-term Pellet Aging}

Mean diameter of pika pellets did not significantly change after 49 days of exposure to field conditions from 27 June to 15 August 2008 ( $P=$ $0.30)$. The exterior color of fresh pellets started out distinctly greenish-brown, and gradually faded. At 49 days, pellets were brown with only a very faint tinge of green. Crushed fresh pellets were initially green inside with some fibrous plant material up to $0.5 \mathrm{~mm}$ long. These pellets tended to hold together when crushed. After only one week, crushed pellets had faded from green to yellow-green and were noticeably more friable. Crushed pellets at 49 days old were similar to 1-week-old pellets in consistency but 
had lost most of their green hue and were mainly yellow.

\section{Long-term Pellet Aging}

Diameters from a total of 2223 pellets from 62 latrines (aged 0-36 years) were measured (Fig. 1). Regression analysis showed a significant negative relationship between mean pellet diameter within latrines and log patch age $\left(\mathrm{R}^{2}=\right.$ $\left.0.76, F_{1,60}=189.6, P<2.2 \times 10^{-16}\right)$. Mean pellet dry mass was determined for the same 2223 pellets and used along with calculated mean pellet volume to construct Figure 2. Regression analysis showed a significant positive relationship between calculated mean pellet volume and mean pellet mass $\left(\mathrm{R}^{2}=0.91, F_{1,60}\right.$ $\left.=608, P<2.2 \times 10^{-16}\right)$.

Pellets $<3$ years old were brown on the exterior. Pellets 3-7 years old were mostly gray. Pellets $>12$ years old were medium to charcoal gray. Interior pellet color, revealed by crushing, matched exterior pellet color regardless of age, except for those $<1$ year old. Pellets $<4$ years old showed the presence of internal fibers. Pellets $>4$ years old were powdery when crushed.

\section{Post hoc Test}

Two independent observers measured diameters of 919 pellets from 24 known-age samples in a blind test. Mean diameters within latrines were not significantly different between the observers $(t=1.20, \mathrm{df}=23, P=0.24)$. Pooled latrine means were $0.201 \mathrm{~mm}$ smaller on average than mean diameters for the same 24 latrines determined in the long-term aging experiment $\left(t=-7.10, \mathrm{df}=23, P=3.12 \times 10^{-7}\right)$. Regression analysis showed a significant negative relationship between mean pellet diameter within latrines and log patch age $\left(\mathrm{R}^{2}=0.57, F_{1,22}=\right.$ 29.63, $P=1.81 \times 10^{-5}$ ) with the following regression equation: mean pellet diameter $(\mathrm{mm})$ $=-0.341 * \log ($ age[years] $)+3.14$.

\section{Discussion}

Fecal pellets of American pikas can persist in talus for decades and may therefore be used to infer recent pika distributions. The results of this study suggest that fecal pellet size, color, and consistency can be used to monitor changes in pika distribution. Studies of fecal pellet decay rates in other organisms and habitat types find persistence times that are much shorter than those reported here for pikas.
Moisture is often singled out as the main factor that influences persistence of mammalian fecal pellets, with higher moisture levels resulting in faster decay rates and shorter persistence times (Wigley and Johnson 1981, Harestad and Bunnell 1987, Prugh and Krebs 2004). Pellets of white-tailed deer (Odocoileus virginianus) in Mississippi disappeared in less than a month during wet seasons (Wigley and Johnson 1981). Harestad and Bunnell (1987) reported that black-tailed deer (Odocoileus hemionus) pellets on Vancouver Island, British Columbia, had essentially all disappeared within 4 years, with the longest persistence time occurring at the driest sites. Pellets of another lagomorph, the snowshoe hare (Lepus americanus), had a mean persistence time of 6 years in Alaska (Prugh and Krebs 2004). In contrast, pellets of American pikas at Bodie may persist for over 36 years. The extreme durability of pika pellets at Bodie is probably due to the combination of aridity and long, cold winters. Mean annual temperature at Bodie is $3.3^{\circ} \mathrm{C}$ and mean annual precipitation is $32.8 \mathrm{~cm}$, mostly falling as winter snow (NCDC 1971-2000).

In addition to decades-long persistence, pika pellets at Bodie shrink as they age (Fig. 1). Determining the cause of pellet shrinkage was not the main purpose of this work; however, some inferences can be drawn from observations reported here. Pellet diameter is probably positively correlated with body size. Reported body mass of adult Bodie pikas varies from $132.2 \mathrm{~g}(n=123)$ measured on deceased individuals collected by shooting (Severaid 1955) to $135.0 \mathrm{~g}(n=100)$ measured on live individuals captured during a mark-recapture study (Peacock 1995). These data indicate no substantial change in body size during the last half of the 20th century. Observed change in pellet size is almost certainly due to factors other than increasing body size. Pellets may shrink over time because of simple desiccation, compression due to seasonal wetting and drying cycles (especially in spring and fall), surface weathering, consumption of the surface by invertebrates, internal decomposition of the pellet by microbial activity, or changes in pika diets over recent decades.

Pellet shrinkage is a slow process. The results of the short-term aging experiment show no significant shrinkage in pellet diameter over the first 49 days of exposure to summer climate in the Great Basin and eastern Sierra Nevada. The 
fitted model in Figure 1 predicts mean pellet shrinkage of $0.04 \mathrm{~mm}$ for this period $(3.67 \mathrm{~mm}$ to $3.63 \mathrm{~mm}$ ), which is less than the accuracy of the calipers used. Pellet diameter shrinks only slightly, even over decades. Over the 36-year period of this study, mean pellet diameter shrank from $3.72 \mathrm{~mm}$ to $2.54 \mathrm{~mm}$ or to $68 \%$ of the original diameter. These observations argue against a simple desiccation hypothesis, as does the continuing reduction of diameter over nearly 40 years. Desiccation would certainly happen rapidly in such a dry climate. If pellets were simply compressing over time, one would expect a reduction in pellet volume without a proportional loss of dry mass. Figure 2 shows that this is not the case. Pellets lose mass in direct proportion to volume.

The mid-20th-century plant community at Bodie reported by Severaid (1955) is the same that occurs now, so changes in pika diets seems an unlikely explanation for changing pellet diameters. Changes in diameter and consistency of pellets in the short-term aging experiment also tends to refute the changing-diets hypothesis since these changes occurred within the same pellets. The fact that internal consistency of pellets changes over time suggests the influence of microbial action in breaking down the pellet internally. Pellets become less fibrous and more powdery. These changes could be attributed to weathering; however, weathering seems more likely to destroy the pellet than to decompose its fibers internally. Slow microbial breakdown of organic material in a pellet's interior, at those times of the year when conditions provide both moisture and above-freezing temperatures, seems the most likely explanation for the observed pattern of fecal pellet shrinkage, although abiotic factors (i.e., oxidation) can not be ruled out.

American pikas represent an ideal organism for monitoring effects of climate change because of their easy detectability, limited heat tolerance, and extreme habitat specificity. A disadvantage to using pikas as an indicator species has been the incompleteness of historical location-specific distribution records. These records are used to examine ongoing distributional changes, especially during the recent period of anthropogenic climate change. Fecal pellets serve as a record of recent pika occupation since they can be easily distinguished from all other sympatric species (Severaid 1955, Smith and Gilpin 1997). Pika pellets have the typical slightly flattened spherical shape characteristic of all lagomorph pellets, yet pika pellets are unique among lagomorphs because of their small size and unique specificity to talus habitats. Individual pikas produce numerous pellets that accumulate at specific latrine sites. Severaid (1955) reported an average of 29 pellets per hour for a captive Bodie pika; however, most pellets produced by unrestrained individuals were deposited in interstitial spaces deep within talus. This rate of production suggests that most pellets must disappear relatively rapidly, even though pellets in the Great Basin can persist for tens of thousands of years when incorporated into woodrat middens (Grayson 1987, 2005, Mead and Spaulding 1995). Long-term studies at Bodie allow for documentation of fecal pellet persistence for more than 36 years in the open and exposed to weather. Pellets at Bodie are protected only in the interstitial space between rocks on 19th- and early 20th-century ore dumps. Those pellets with long persistence times may simply have been deposited in favorable locations where they are unlikely to wash or blow out of the talus. The enormous number of identifiable pellets produced per individual, combined with pellet durability, allows timing of pika occupation to be documented even decades after their extinction.

Recency of pika occupation can be estimated by examining pellet characteristics. Pellets deposited within a week are easily identified by color and consistency. Using qualitative changes in pellet diameter and color to date relatively fresh pellets requires much direct experience by individual researchers; however, even without extensive experience, researchers can distinguish fresh pellets from old pellets by using color. This method provides a simple system to determine whether a patch is currently occupied and is similar to that used for snowshoe hare (Lepus americanus) in Alaska (Prugh and Krebs 2004). Given the qualitative changes in pellet color and internal consistency that occur over several years, an experienced researcher could reasonably classify pellets as "fresh" (deposited within the past week), "moderately fresh" (a week to several months old), "moderately old" (several months to 4 years old), "old" (5 years to 12 years old), or "very old" (older than 12 years).

The observation that mean pellet diameter shrinks over decades allows an objective estimate of the time elapsed since pellets were 
produced (Fig. 1). Dating methods using radioisotopes are useful only for millennial time scales (but see Geyh 2001 for a possible radiometric dating method useful for organic samples from mid-20th century to present). Using the mean pellet diameter allows age estimates on decadal timescales, which is much more useful for monitoring recent changes in pika distributions in light of ongoing anthropogenic climate change.

Several factors may bias extirpation timing estimates using pellet diameters. The pellets sampled may not always be the most recent ones left at a latrine site. I collected the most superficial pellets, although it is possible that wind or animal activity could have brought deeper (and presumably older) pellets to the surface of a latrine. This process would increase the variance of a sample, but it is unclear how to avoid the problem. Pellets left by subadults and juveniles might bias a sample toward an older age estimate (ignoring internal consistency and color of pellets) because subadults and juveniles presumably produce smaller pellets than adults. The short time span between weaning and achieving adult body mass (approximately 2 months) relative to life expectancy (5-6 years) (Smith and Weston 1990) suggests that in a patch adult-sized animals produce the most pellets. This potential bias is lessened further if the last survivor on a patch is usually an adult. Pellets left by transient individuals could also bias estimates of patch extirpation timing, although high territorial fidelity and limited dispersal ability reduce the possibility of finding these pellets in quantities sufficient to influence patch extirpation estimates (Smith 1974a).

The lack of known-age pellet samples from other Great Basin pika populations greatly limits the possibility of independently testing the diameter-versus-age relationship reported here; however, several observations support the potential utility of this method. On 24 June 2003, I visited a talus patch at the top of Bodie Mountain (3106 m elevation) approximately $5 \mathrm{~km}$ northwest of Bodie. Amid much old sign, one territory contained fresh pellets; and I concluded that it was occupied. I visited this site again on 29 June 2008 and found only old sign. Forty randomly selected pellets collected from this territory had a mean diameter of $3.23 \mathrm{~mm}$. Figure 1 estimates the extirpation date for this patch in the last half of 2003. Mean diameter of the pellets used in the short-term aging experiment was determined 412 days after the experiment began. This data point falls where predicted by regression (designated by $\mathrm{X}$ in Fig. 1). The post hoc test also confirmed that the negative relationship between mean pellet diameter and age is robust, even though pellets continued to shrink when removed from the field and stored. The regression equation reported in the post hoc test is similar to that in Figure 1.

While variance in pellet diameter limits the accuracy of time estimates, useful estimates of last-known occupation should be possible to the nearest $5-10$ years (Fig. 1). This method should be applicable throughout the Great Basin and may also be useful in other montane habitats; however, future research is required to define the limits of its general applicability. Recalibration would probably be required in habitats with very different climate regimes or where resident pika populations significantly differ in mean body mass from those at Bodie.

\section{ACKNOWLEDGMENTS}

J. Bland and D. Grayson provided insightful discussions relating to the design of this project. E. Baker, E. Beever, D. Grayson, A.T. Smith, and 3 anonymous reviewers gave helpful comments and criticisms on earlier drafts of this manuscript. P. Nichols provided helpful discussions, help with fieldwork, and endless encouragement. R. Cobb furnished technical support for the laboratory portion of this project. I am grateful to J. Moss and B. Moss, who volunteered to spend hours measuring hundreds of pellets in a blind test. Special thanks to the staff and volunteers of Bodie State Historic Park for moral and logistical support over many years. This project would not have been possible without the unflinching, long-term support of Bodie Supervising Rangers B. Sturdivant and M. Langner.

\section{Literature Cited}

Beever, E.A. 2002. Persistence of pikas in two low-elevation national monuments in the western United States. Park Science 21:23-29.

Beever, E.A., P.F. Brussard, and J. Berger. 2003. Patterns of apparent extirpation among isolated populations of pikas (Ochotona princeps) in the Great Basin. Journal of Mammalogy 84:37-54.

Beever, E.A, J.L. Wilkening, D.E. McIvor, S.S. Weber, AND P.F. BRussard. 2008. American pikas (Ochotona princeps) in northwestern Nevada: a newly discovered population at a low-elevation site. Western North American Naturalist 68:8-14. 
Bole, B.P., JR. 1938. Some high altitude records for mammals in the Inyo-White mountains of California. Journal of Mammalogy 19:245-246.

Carlson, J., JR. 2008. California Fish and Game Commission - notice of findings. Formal findings adoption on 27 June 2008, Upland, CA. Available from: http:/www .fgc.ca.gov/regulations/new/2008/apfindingsreject.pdf

Clinchy, M., D.T. Haydon, and A.T. Smith. 2002. Pattern does not equal process: what does patch occupancy really tell us about metapopulation dynamics? American Naturalist 159:351-362.

DurRant, S.D. 1952. Mammals of Utah: taxonomy and distribution. University of Kansas Publications, Museum of Natural History 6:1-549.

GEYH, M.A. 2001. Bomb radiocarbon dating of animal tissues and hair. Radiocarbon 43:723-730.

Grayson, D.K. 1987. The biogeographic history of small mammals in the Great Basin: observations on the last 20,000 years. Journal of Mammalogy 68:359-375.

2005. A brief history of Great Basin pikas. Journal of Biogeography 32:2103-2111.

GRINnELL, J. 1918. Six new mammals from the Mohave Desert and Inyo regions of California. University of California Publications in Zoology 17:423-430.

Hafner, D.J., And R.M. Sullivan. 1995. Historical and ecological biogeography of Nearctic pikas (Lagomorpha: Ochotonidae). Journal of Mammalogy 76:302 315.

HaLl, E.R. 1946. Mammals of Nevada. University of California Press, Berkeley, CA.

1951. A synopsis of the North American Lagomorpha. University of Kansas Publications, Museum of Natural History 5:1-202.

Harestad, A.S., And F.L. Bunnell. 1987. Persistence of black-tailed deer fecal pellets in coastal habitats. Journal of Wildlife Management 51:33-37.

HowelL, A.H. 1924. Revision of the American pikas. North American Fauna 47:1-57.

MacArthur, R.A., AND L.C.H. WANG. 1973. Physiology of thermoregulation in the pika, Ochotona princeps. Canadian Journal of Zoology 51:11-16.

MEad, J.I., AND W.G. SPAulding. 1995. Pika (Ochotona) and paleoecological reconstructions of the Intermountain West, Nevada and Utah. Pages 165-186 in D.W. Steadman and J.I. Mead, editors, Late Quaternary environments and deep history: a tribute to Paul S. Martin. Scientific Paper 3, Mammoth Site, Hot Springs, SD.

Moilanen, A., A.T. Smith, AND I. Hanski. 1998. Long-term dynamics in a metapopulation of the American pika. American Naturalist 152:530-542.

Moritz, C., J.L. Patton, C.J. Conroy, J.L. Parra, G.C. WhITE, AND S.R. BEISSINGER. 2008. Impact of a century of climate change on small-mammal communities in Yosemite National Park, USA. Science 322:261-264.

Morrison, S.F., AND D.S. Hik. 2008. When? Where? And for how long? Census design considerations for an alpine lagomorph, the collared pika (Ochotona collaris). Pages 103-113 in P.C. Alves, N. Ferrand, and K. Hacklander, editors, Lagomorph biology: evolution, ecology, and conservation. Springer-Verlag, Berlin/ Heidelberg, Germany.

[NCDC] National Climatic Data Center. 1971-2000. Monthly normals, Bodie California. Western Regional Climate Center, Reno, NV. Available from: http://www .wrcc.dri.edu/cgi-bin/cliNORMNCDC2000.pl ?cabodi
PEACOCK, M.M. 1995. Dispersal patterns, mating behavior, and population structure of pikas (Ochotona princeps). Doctoral dissertation, Arizona State University, Tempe, AZ.

1997. Determining natal dispersal patterns in a population of North American pikas (Ochotona princeps) using direct mark-resight and indirect genetic methods. Behavioral Ecology 8:340-350.

PEACOCK, M.M., AND A.T. Smith. 1997. The effect of habitat fragmentation on dispersal patterns, mating behavior, and genetic variation in a pika (Ochotona princeps) metapopulation. Oecologia 112:524-533.

Prugh, L.R., AND C.J. KREBs. 2004. Snowshoe hare pelletdecay rates and aging in different habitats. Wildlife Society Bulletin 32:386-393.

R Development Core Team. 2008. R: a language and environment for statistical computing. Vienna, Austria. Available from: http://www.r-project.org

RaY, C., AND E. BEEver. 2007. Distribution and abundance of the American pika (Ochotona princeps) within Lava Beds National Monument. U.S. Department of the Interior, National Park Service, Final Report.

Severaid, J.H. 1955. Natural history of the pikas (Mammalian genus Ochotona). Doctoral dissertation, University of California at Berkeley, CA.

SImPSON, W.G. 2009. American pikas inhabit low-elevation sites outside the species' previously described bioclimatic envelope. Western North American Naturalist 69:243-250.

Smith, A.T. 1974a. The distribution and dispersal of pikas: consequences of insular population structure. Ecology 55:1112-1119.

1974b. The distribution and dispersal of pikas: influences of behavior and climate. Ecology 55:13681376.

1980. Temporal changes in insular populations of the pika (Ochotona princeps). Ecology 61:8-13.

Smith, A.T., AND M. GILPIN. 1997. Spatially correlated dynamics in a pika metapopulation. Pages 407-428 in I.A. Hanski and M.E. Gilpin, editors, Metapopulation biology: ecology, genetics, and evolution. Academic Press, San Diego, CA.

SMITH, A.T., AND B.L. IvINs. 1983. Colonization in a pika population: dispersal vs philopatry. Behavioral Ecology and Sociobiology 13:37-47.

1984. Spatial relationships and social organization in adult pikas: a facultatively monogamous mammal. Zeitschrift für Tierpsychologie 66:298-308.

Smith, A.T., AND M.L. Weston. 1990. Ochotona princeps. Mammalian Species 352:1-8.

Verts, B.J., AND L.N. CarRaWAY. 1998. Land mammals of Oregon. University of California Press, Berkeley, CA.

Wigley, T.B., AND M.K. Johnson. 1981. Disappearance rates for deer pellets in the Southwest. Journal of Wildlife Management 45:251-253.

Wolf, S., B. Nowicki, and K. Siegal. 2007. Petition to list the American pika (Ochotona princeps) as threatened under the California Endangered Species Act Center for Biological Diversity [petitioner], 1095 Market St., Suite 511, San Francisco, CA. August 21, 2007. Available from: http://www.biologicaldiversity.org/ species/mammals/American_pika/pdfs/petition_ca2007.pdf

Received 20 March 2009 Accepted 26 April 2010 